Exercices Exercices de rhétorique

de rhétorique $14 \mid 2020$

La polémique chez les Pères de l'Église

\title{
Lettre 17
}

Traduction par Émilie Balavoine

Jérôme

\section{(2) OpenEdition}

Journals

Electronic version

URL: http://journals.openedition.org/rhetorique/981

DOI: $10.4000 /$ rhetorique.981

ISSN: 2270-6909

\section{Publisher}

UGA Éditions/Université Grenoble Alpes

\section{Printed version}

ISBN: 978-2-37747-186-7

Electronic reference

Jérôme, «Lettre 17 », Exercices de rhétorique [Online], 14 | 2020, Online since 04 March 2020, connection on 12 September 2020. URL : http://journals.openedition.org/rhetorique/981 ; DOI : https://doi.org/10.4000/rhetorique.981

This text was automatically generated on 12 September 2020

\section{(c) (i) (2)(2)}

Les contenus de la revue Exercices de rhétorique sont mis à disposition selon les termes de la Licence Creative Commons Attribution - Pas d'Utilisation Commerciale - Partage dans les Mêmes Conditions 4.0 International. 


\title{
Lettre 17
}

\author{
Traduction par Émilie Balavoine
}

\section{Jérôme}

Dans cette courte lettre datée d'avant 380, Jérôme qui vit en ermite dans le désert de Chalcis, s'adresse à Marc, prêtre à Chalcis, pour l'assurer à nouveau de sa foi et lui rendre compte de la difficile situation qui est la sienne. Les moines des alentours n'ont de cesse de l'interroger sur sa foi et plus précisément sur la question de la traduction du terme homoousia (" de même nature »). Jérôme est alors accusé d'être hérétique. En réponse à ces accusations, Jérôme, qui se présente comme malade et fatigué, utilise de nombreuses stratégies argumentatives et polémiques pour convaincre son lecteur de sa bonne foi et montrer la violence de la situation qu'il subit, et qui le contraint à envisager son départ du désert de Chalcis pour Antioche.

\section{À Marc, prêtre à Chalcis / Ad Marcum presbyterium Chalcide}

1. J'avais certes décidé d'utiliser cette parole du psalmiste: Comme le pécheur se tenait face à moi,je restai silencieux et je me suis humilié et j'ai gardé le silence loin des gens de bien et encore moi, comme un sourd, je n'entendais pas et comme un muet qui n'ouvre pas la bouche, je suis devenu comme un homme qui n'entend pas ; mais puisque la charité surpasse tout et que mon affection l'emporte sur ce projet, je réponds à ta requête plus que je ne rends la pareille à ceux qui me font injure. Chez les chrétiens, en effet, ce n'est pas celui qui souffre, comme le dit une certaine personne, mais celui qui outrage qui est malheureux.

1. Decreueram quidem utendum mihi psalmistae uoce dicentis: Cum consisteret aduersum me peccator, obmutui et humiliatus sum et silui a bonis ${ }^{1}$ et iterum: Ego uero tamquam surdus non audiebam et tamquam mutus non aperiens os suum factus sum ut homo non audiens ${ }^{2}$, sed quoniam caritas omnia superat et propositum 
uincit affectus, non tam iniuriam facientibus reddo uicem, quam tibi respondeo postulanti.

Apud Christianos enim non qui patitur, ut ait quidam, sed qui facit contumeliam, miser est.

2 2. Et d'abord, avant que je ne te parle de ma foi que tu connais très bien, je suis contraint de crier contre la barbarie qui règne en ces lieux par ces vers bien connus :

Quelle est cette sorte d'hommes? Quelle patrie si barbare

autorise cette coutume? On nous refuse l'hospitalité du sable, on nous fait la guerre, on nous défend même de nous installer sur l'extrême bord du rivage, etc. Ces propos, nous les avons empruntés à un poète profane pour que celui qui ne conserve pas la paix du Christ apprenne au moins d'un païen la paix. On m'appelle hérétique, moi qui prêche la Trinité homoousia (de même nature), je suis accusé de l'impiété de Sabellius moi qui proclame d'une voix infatigable qu'il y a trois personnes subsistantes, vraies, entières et parfaites. Si cela vient des Ariens, d'accord ; mais si cela vient des orthodoxes, ceux qui accusent une telle foi ont cessé d'être orthodoxes ou, s'ils le veulent, qu'ils me condamnent comme hérétique avec l'Occident, hérétique avec l'Égypte, c'est-à-dire avec Damase et Pierre. Pourquoi incriminent-ils un seul homme et non pas ses compagnons? Si un ruisseau coule faiblement, ce n'est pas la faute du lit, mais de la source. J'ai honte de le dire : du fond des grottes qui nous servent de cellules, nous condamnons le monde, lorsque, roulés dans le sac et la cendre, nous portons un jugement sur des évêques.

Que fait l'âme d'un roi sous la tunique d'un pénitent ? La chaîne, la crasse et la masse de tes cheveux ne sont pas les marques du diadème mais des pleurs, oui. Qu'ils me permettent, je les en prie, de ne rien dire. Pourquoi déchirent-ils un homme qui ne mérite pas la haine? Je suis hérétique: qu'est-ce que cela peut te faire? Reste tranquille, on l'a déjà dit. Tu crains sans doute qu'en homme très éloquent en syriaque ou en grec, je ne fasse le tour des églises, je n'égare les peuples, je ne réalise un schisme. Je n'ai rien pris à personne, en ne travaillant pas, je ne reçois rien. C'est avec nos mains chaque jour et avec notre propre sueur que nous cherchons de la nourriture, connaissant ce qu'a écrit l'Apôtre : Celui qui ne travaille pas, qu'il ne mange pas.

2. Et primo quidem, antequam de fide mea, quam optime nosti, tecum loquar, aduersus barbariam istius loci uersu cogor clamare uulgato:

Quod genus hoc hominum? quaeue hunc tam barbara morem

permittit patria? hospitio prohibemur arenae.

bella cient primaque uetant consistere terra ${ }^{3}$

et cetera. Quae idcirco de gentili poeta sumpsimus, ut qui Christi pacem non seruat, pacem saltim discat ab ethnico. Haereticus uocor homousiam praedicans trinitatem; Sabellianae inpietatis arguor tres subsistentes, ueras, integras perfectasque personas indefessa uoce pronuntians. Si ab Arrianis, merito; si ab orthodoxis, qui huiusmodi arguunt fidem, esse orthodoxi desierunt aut, si eis placet, hereticum me cum occidente, hereticum cum Aegypto, hoc est cum Damaso Petroque, condemnent. Quid unum hominem exceptis sociis criminantur? Si riuus tenuiter effluit, non est aluei culpa, sed fontis. Pudet dicere: de cauernis cellularum damnamus orbem, si in sacco et cinere uolutati de episcopis sententiam ferimus.

Quid facit sub tunica paenitentis regius animus? Catena, sordes et comae non sunt diadematis signa, sed fletus. Permittant mihi, quaeso, nihil loqui. Cur eum lacerant, qui non meretur inuidiam? Hereticus sum : quid ad te? Quiesce, iam dictum est. Plane times, ne eloquentissimus homo in Syro sermone uel Graeco ecclesias circumeam, populos seducam, scisma conficiam. Nihil alicui praeripui, nihil otiosus accipio. Manu cotidie et proprio sudore quaerimus cibum scientes ab apostolo scriptum esse: Qui autem non operatur, nec manducet ${ }^{4}$. 
3 3. Ces paroles, père vénérable et saint, avec quels gémissements, avec quelle douleur je les ai écrites, Jésus m'en est témoin.

Je me suis tu, me tairai-je toujours? dit le Seigneur. On ne me concède pas un seul recoin du désert. Quotidiennement on me réclame ma foi, comme si j'étais régénéré sans foi. Je la fais comme ils la veulent : elle ne convient pas. J'y appose ma signature : ils ne me croient pas. Cela seul leur plaît, que je m'en aille d'ici. Je suis sur le point de m'en aller. Ils m'ont arraché une partie de mon âme, des frères très chers. Voici qu'ils désirent s'en aller, ou mieux, ils s'en vont en disant qu'il vaut mieux habiter parmi les bêtes sauvages plutôt qu'avec de tels chrétiens ; moi aussi, si la faiblesse de mon corps et la dureté de l'hiver ne me retenaient, je fuirais tout de suite. Cependant, en attendant qu'arrive le printemps, de grâce, que pour quelques mois l'hospitalité du désert me soit accordée ; ou si cela aussi leur semble tard, je m'en vais. Au Seigneur est la terre et tout ce qui l'emplit. Que seuls ils montent au ciel, que le Christ ne soit mort que pour eux, qu'ils aient (ces terres), qu'ils les possèdent, qu'ils s'en glorifient ; loin de moi de me glorifier sinon dans la croix de notre Seigneur Jésus Christ, par qui le monde est crucifié pour moi et moi pour le monde.

3. Haec, uenerabilis et sancte pater, cum quali gemitu, cum quali dolore conscripserim, testis est Iesus.

Tacui, numquid semper tacebo ${ }^{5}$ ? dicit Dominus. Non mihi conceditur unus angulus heremi. Cotidie exposcor fidem, quasi sine fide renatus sim. Confiteor, ut uolunt : non placet. Subscribo: non credunt. Unum tantum placet, ut hinc recedam. Iam iam cedo. Abruperunt a me partem animae meae, carissimos fratres. Ecce discedere cupiunt, immo discedunt melius esse dicentes inter feras habitare, quam cum talibus Christianis; et ego ipse, nisi me et corporis inbecillitas et hiemis retineret asperitas, modo fugerem. Verumtamen, dum uernum tempus adueniat, obsecro, ut paucis mihi mensibus heremi concedatur hospitium; aut si et hoc tardum uidetur, abscedo. Domini est terra et plenitudo eius ${ }^{6}$ ascendant soli caelum, propter illos tantum Christus mortuus sit, habeant, possideant, glorientur; Mihi autem absit gloriari nisi in cruce Domini nostri Iesu Christi, per quem mihi mundus crucifixus est et ego mundo 7 .

4. Quant à ma foi, parce que tu as daigné m'écrire à ce sujet, j'ai donné par écrit ma foi pour saint Cyrille. Celui qui ne croit pas de la sorte est étranger au Christ. Du reste, moi, j'ai pour témoins de ma foi tes oreilles et celles du bienheureux frère Zénobe, à qui, en même temps qu'à toi, nous adressons, nous tous qui sommes ici, toutes nos salutations.

4. De fide autem quod dignatus es scribere, sancto Cyrillo dedi conscriptam fidem. Qui sic non credit, alienus a Christo est. Ceterum ego fidei meae testes habeo aures tuas et beati fratris Zenobii, quem te cum omnes, qui hic sumus, plurimum salutamus.

\section{NOTES}

1. Ps. 39 (38), 2-3.

2. Ps. 38 (37), 14-15.

3. Virgile, Énéide I, 539-541.

4. 2 Th. $3,10$.

5. Is. 42,14 .

6. Ps. 23 (24), 1.

7. Ga. $6,14$. 


\section{AUTHOR}

JÉRÔME

Jérôme de Stridon (c. 347 - 420) 